\title{
Comunicación

\section{Construcción de la identidad femenina en programas de belleza radiofónicos}

Se analiza el concepto de identidad y cómo se construye una identidad femenina en programas radiofónicos de corte frívolo. Lejos de constituir una diversión intrascendente, los programas radiofónicos frívolos contienen una serie de estrategias sociosemióticas que se difunden como constitutivas del grupo femenino. Las estrategias sociosemióticas identificadas son: la actuación, la diversión y la ignorancia. Las hablantes utilizan el discurso directo para "actuar", las bromas para ser "divertidas" y construcciones discursivas propias de alguien lo suficientemente "ignorante" para parecer lo suficientemente femenina.

PALABRAS CLAVE: identidad femenina, discurso, estrategia, sociosemiótica.
The identity concept is analyzed and how a feminine identity in a wireless programs of frivolous cut is constructed. Far from constituting an insignificant diversion, frivolous wireless programs contain a series of sociosemiotics strategies that spread like constituent of the feminine group. The sociosemiotics strategies we recognized are: the "performance", the "diversion" and the "ignorance". The speakers use the direct speech for "acting", the jokes "to be amused" and discursive constructions of somebody the sufficiently "ignorant" to seem the sufficiently feminine.

KEY WORDS: feminine identity, speech, strategy, sociosemiotics.

* Universidad de Guadalajara.

Correo electrónico: pca98@cencar.udg.mx 


\section{PLANTEAMIENTO}

Referirse a la identidad femenina puede resultar una osadía, porque la referencia implicaría que sólo existe una forma de construirse socialmente como mujer. No obstante, esta limitación parece apartarse cuando constatamos que en distintos países existe una discusión permanente sobre el desempeño psicológico y social de la mujer en distintas circunstancias. Diversos planteamientos públicos nos avisan que la identidad femenina está en proceso de cambio. En España la violencia doméstica hacia la mujer y los porcentajes equitativos de representatividad femenina en los puestos gubernamentales, mientras que en México se ha discutido, últimamente, sobre los derechos políticos de las esposas de gobernantes y los asesinatos sistemáticos no resueltos de mujeres jóvenes en Ciudad Juárez. Sin embargo, el estado de cambio, de crisis de la identidad femenina no es simétrico en las distintas regiones; los problemas sociales y económicos específicos conducen diferenciadamente la discusión. En México, aunque también se ha discutido, sin hacerse realidad, la necesidad de que exista una representatividad femenina equitativa en los puestos gubernamentales, no se ha planteado la violencia doméstica como un problema de género; en todo caso se ha planteado la violencia, en su dimensión privada, como un problema infantil; los niños aparecen como la parte más vulnerable en la violencia doméstica, lo cual, sin dejar de corresponder a la realidad, es simultáneo a una insuficiente atencion de la violencia doméstica contra la mujer.

Por otra parte, en el contexto de la cultura global, aparecen una serie de modelos mediáticos trasnacionales en los que se reproducen símbolos y todo tipo de representaciones ideológicas que propagan formas grupales unívocas de ser. De ahí que la identidad ${ }^{1}$ femenina se ma-

1 El concepto "procesos de identificación" ha sido propuesto por Balibar (2005: 39) como un concepto alternativo a "identidad". Balibar sostiene que ninguna identidad es adquirida de manera permanente. Los procesos de identidad nos remiten a construcciones simbólicas en constante movimiento, de acuerdo a entornos espaciales y temporales. La visión de Balibar es importante porque acoge la complejidad de la persona en los contextos urbanos contemporáneos: somos en movimiento y las identificaciones re- 
nifieste, por un lado, como una conformación con matices regionales que determina el contexto socioeconómico y la cultura propia del grupo $\mathrm{y}$, por otro, como una conformación estándar en la que se comparten significados y símbolos globales.

En este trabajo abordaré la construcción de la identidad femenina en los programas de belleza radiofónicos. El análisis del cuerpo de datos, como podrá apreciarse, muestra precisamente ese doble filo: encontramos matices regionales en la conformación de la identidad femenina, pero también esas variantes que se comparten en la construcción global de la identidad femenina.

De manera particular, analizo un conjunto de siete grabaciones del programa "Frivolidades", realizadas entre el 4 y 14 de febrero de 2002. Este programa se transmite diariamente de 9 a 10 de la mañana, de lunes a viernes, conducido por quien únicamente se identifica como "Griseld". La estación que acoge este programa es Radio Mujer, ubicada en el cuadrante 1040 de AM, XEBBB-AM; se transmite en las ciudades de Guadalajara y Mazatlán, en la replública mexicana. Esta estación pertenece al grupo Promomedios de Occidente, S.A. de C.V. El programa se autodefine como "programa de belleza".

\section{LA IDENTIDAD FEMENINA}

El concepto de identidad es un concepto que se ha utilizado con diversos sentidos. La identidad puede abordarse como un fenómeno individual y como un fenómeno social. Asumiendo el sentido común, diríamos que la identidad son los rasgos, con los que se identifica a una persona o a un

currentes propician una identidad con la que atinamos a vernos a nosotros mismos, y con las que los otros atinan a vernos como personas miembros de grupos. Por otro lado, es preciso señalar que la identidad, como concepto que recoge un proceso de identificación grupal, tenderá a la construcción de estereotipos. El estereotipo es altamente productivo cuando realizamos apreciaciones coloquiales, rápidas, sobre los otros y sobre lo otro. Semióticamente el estereotipo puede concebirse como una síntesis apreciativa sobre los otros, sobre personas y grupos, que se construye con atributos semánticos (significados) subjetivos (Córdova, 2003). 
grupo, siendo tales rasgos, "idénticos" a la imagen mental que tiene la persona o el grupo de sí mismo. Es decir, la identidad se construye por los sujetos mismos, pero también es co-construida por los otros grupos que interactúan con los sujetos o grupos en cuestión. Un grupo confirma su identidad a partir de las respuestas que obtiene de los otros, y tales respuestas pueden ser tanto de aceptación o de rechazo como ambivalentes.

El problema del concepto de identidad, sin embargo, se encuentra no en el enfoque individual o social que se le dé al mismo, sino en el atribuir su existencia a un "conjunto de rasgos" y a la operación de identificación en sí misma. En el primer caso, los rasgos podrían ser proposiciones modales con las que se identifica un grupo; por ejemplo, las mujeres, según su pertenencia social, pueden conformar su identidad con proposiciones como "las mujeres deben trabajar" o, en oposición, "las mujeres deben cuidar siempre de sus hijos". Pero los rasgos cuya conjunción forma una identidad no sólo pueden ser proposiciones, pueden ser símbolos compartidos, actitudes, acciones que pueden ser prácticas laborales y de esparcimiento, entre otras. De tal manera que la identidad de una mujer puede contener, además, el uso de símbolos como portar argolla de matrimonio o no portarla, vestir de mezclilla o traje sastre; trabajar como profesora universitaria o trabajar como mucama; inscribir a sus hijos en clases de natación y de idiomas o no hacerlo. En ese sentido, la identidad deviene en un concepto cuya constitución epistemológica es abstracta porque alude a datos diversos y difusos. En este caso, la identidad se mezcla con el sustrato de ideología que inevitablemente contiene, pues la identidad comparte y restringe elementos simbólicos con respecto a otros grupos, según sea el enfoque con el que se esté abordando.

Teun A. van Dijk ha señalado que la identidad puede ser entendida como una extensión hacia el amplio mundo de las prácticas sociales, símbolos y organización, lo que conduciría a un concepto de uso tan vago como el de cultura, pero también, a decir del autor, la identidad puede ser restringida al "núcleo compartido de la autodefinición social, es decir, a un conjunto de representaciones sociales que los miembros consideran específicas de su grupo.”(1999:160). Mi punto de vista, al respecto, es que un concepto puede tener una dimensión epistemológica más abstracta o más concreta, sin por ello demeritar su calidad en el 
uso analítico ${ }^{2}$. Es preciso que la identidad de los grupos se aborde en su resonancia amplia y en su resonancia particular, como "autodefinición social", en este caso. Sin embargo si intentáramos limitar la identidad a una autodefinición social, estaríamos dejando de lado la visión de los otros sobre el grupo en cuestión y estaríamos circunscribiendo el material analítico a la "definición” del sí mismo y, por lo tanto, a los datos verbales.

Autores disímiles por disciplina y tiempo de vida, como Bajtín, Bourdieu y Marina, han abordado el concepto de identidad precisamente en una versión epistemológica abstracta y, por ello, enriquecedora. Comprender que la contemplación de los otros ayuda a la autodefinición y que son ciertos rasgos y no la totalidad lo que siempre se desvela de la identidad (Bajtín, 2000), asumir que los grupos sociales coexisten en espacios simbólicos por medio de relaciones de fuerza entre unos y otros (Bourdieu, 1990 y 2000), y pretender que la conformación de la identidad es un problema filosófico que debe discutirse (Marina, 2000), son perspectivas que ensanchan positivamente el análisis de la identidad.

En este trabajo me interesa abordar la identidad femenina en las dos modalidades presentadas. En cuanto a las formas indirectas de avenir una identidad grupal, en programas radiofónicos realizados por mujeres y para mujeres, con formato semiformal, en los que abunda el habla semiespontánea, he encontrado representaciones discursivas específicas como la estrategia sociosemiótica de la ignorancia, la estrategia sociosemiótica de la actuación y la estrategia sociosemiótica de la diversión, que funcionan como acciones pragmáticas y símbolos que trazan, de manera indirecta, un tipo de identidad femenina. No todas las mujeres utilizan estas estrategias sociosemióticas, o es probable que las

2 Existe cierta actitud concretista en los estudios del discurso que, sin lugar a dudas, es herencia del estructuralismo lingüístico. Según esta actitud es necesario identificar los fenómenos discursivos específicos que funcionan en el texto de manera sistemática, ya sea en el plano micro, macro o superestructural (Van Dijk, 1983). Su estrategia analítica puede variar según sea el caso. Sin embargo, esto no debe significar desterrar los conceptos que permiten una visión más abstracta del problema: aquella en la que se analiza el eslabón entre texto y contexto extraverbal. 
utilicen sólo en ciertas situaciones enunciativas. Este hecho es la prueba fehaciente de que no existe sólo una identidad femenina, y de que varía no sólo por características subgrupales (profesión, edad, estado civil, nivel económico, nivel cultural, etcétera) sino por el contexto diafásico, es decir por las necesidades de estilo y registro discursivo que en cada momento enunciativo aparecen.

El concepto de estrategia sociosemiótica está inspirado en la sociosemántica de Halliday (1982), perspectiva en la que el autor se coloca para explicar cómo el lenguaje del niño se desarrolla respecto a un número de funciones sociales que conforman, a su vez, un entorno semiótico. Nuestra estrategia sociosemiótica se refiere a nudos discursivos recurrentes en los que es constante un significado y una actitud del hablante. Hacer alusión frecuente a la ignorancia, a la actuación o a la diversión, ya sea escenificándolas o nombrándolas, se convierten en estrategias simbólicas que caracterizan a un grupo y que, por lo tanto, se convierten en elementos constitutivos de su identidad.

En lo que respecta a las formas directas de autodefinición grupal, en el sentido de manifestar qué representaciones sociales singulares consideran las mujeres como adecuadas o inadecuadas para su propio grupo, tenemos, de entrada, el hilo conductor de los programas analizados: una mujer debe ser bella o, al menos, debe esforzarse por serlo. Al mismo se agregan: una mujer debe pensar siempre en los otros, gustar a los otros y ser divertida. Esta consigna de identificación, de identidad, que se ha encontrado en el análisis, confirma lo ya señalado por distintas analistas de género, a saber, que la mujer ha sido tradicionalmente educada para satisfacer el gusto y las expectativas de los otros y no las suyas propias (Martín Rojo, 1996).

\section{EL DISCURSO COMO TEJIDO CONSTITUTIVO DE LA IDENTIDAD FEMENINA}

El discurso es una representación social a través del cual se manifiestan, directa o indirectamente, las diversas identidades implicadas en un evento comunicativo. Los discursos emitidos por mujeres tendrán siempre huellas de su identidad. Claro está que tratándose de textos científicos o textos donde existe una decidida voluntad de borrar las 
marcas enunciativas, se desvanecerán las posibles marcas del sexo del hablante. En estos casos los textos son susceptibles de análisis en función de regulaciones pragmáticas y discursivas ${ }^{3}$ que no se explican por la pertenencia sexual del hablante.

La relación entre discurso y sexo del hablante ha sido motivo de una amplia bibliografía. De manera particular, se ha pretendido revisar la manera en que cierta discriminación hacia las mujeres se ha asentado no sólo en variaciones discursivas, sino en variaciones de la lengua. El hecho de que en lenguas como el español, la no marca de género ${ }^{4}$ se manifieste con terminaciones que también corresponden al masculino, ha dado origen a la explicación suspicaz y a la exigencia de que se eliminen ciertas variantes morfológicas de la lengua en las

3 Existe un tejido social discursivo cuyas realizaciones se ordenan de acuerdo a la utilidad social e ideológica que en sí mismas representan. Las realizaciones responden a ordenamientos complejos del individuo, del hablante; estas realizaciones son complejas porque un hablante no es unidimensional; un individuo será capaz de hablar como profesor, padre de familia, amigo, hijo, directivo, entrenador, etcétera, según sean sus necesidades y capacidades sociales. Este hecho social determina que el saber lingüístico sea insuficiente para analizar los discursos. Las palabras son instrumentos que limitan o expanden la identidad; de ahí que podamos afirmar que también un hablante femenino no siempre hablará como mujer; podrá hablar como médico, como investigadora, o como la circunstancia sociodiscursiva exija y su formación cultural le permita.

4 Los lingüistas estructuralistas argumentan que en español lo no marcado es el masculino. Esto implicaría que cuando decimos "señores" o "niños" en un auditorio donde de hecho se encuentras hombre y mujeres, estamos siendo correctos porque gramaticalmente lo no marcado es el masculino. En la realidad discursiva las cosas no son así. Recuerdo una reunión preescolar en que quien presidía dijo: "Levántense los niños", y mi pequeña hija de cinco años me preguntó: "Mamá, ¿las niñas no?” Como hablante adulto yo entendía que cuando se dice niños, se incluye a las niñas, pero como hablante novel, una pequeña intuye lingüísticamente que /a/ no es igual a /o/. Este hecho estaría indicando que la adecuación social del discurso no corresponde a la corrección gramatical de la lengua. 
que la neutralidad de género puede expresarse con un morfema distinto al que corresponde al género masculino (por ejemplo: decir "la humanidad" en lugar de "el hombre"con sentido genérico). Posiciones extremas son aquellas en las que se confunde el género gramatical $^{5}$ con el sexo mismo, como sucede cuando se afirma que es sexista decir "los maestros" y no "los maestros y las maestras", si el referente incluye maestros de ambos sexos. Algunos gramáticos enfocan este problema como un problema de ignorancia gramatical (Gónzalez Calvo, 1998), mientras que lingüistas de tendencia feminista explican que el hecho de que indistintamente se utilice el masculino en expresiones en las que se puede neutralizar la referencia al masculino, provoca que la mujer interprete que el mundo sobre el que está leyendo, o escuchando, se le presente como un mundo ajeno a su realidad y a sus posibilidades (Lakoff, 1981). En contraste aparece el fenómeno de la fetichización del género gramatical, según el cual algunas mujeres se niegan a aceptar el marcador de género femenino en la palabra que designa su profesión porque el marcador de género masculino contaría con un mayor prestigio encubierto; así se negarían a usar directora, ingeniera y médica y optarían por pedir que se les refiera como director, ingeniero y médico (García Mouton, 1999).

Más allá de la polémica sobre estas variantes morfoléxicas, está el caso de las estrategias discursivas que han sido señaladas como características de una identidad femenina y que, sin lugar a dudas, muestran que hasta hace muy poco el ejercicio del poder en la cultura occidental estaba sólo en manos de los hombres.

La identidad femenina se moldea, en principio, con un conjunto de estrategias discursivas y simbólicas que son permitidas y alentadas para dotar, a las niñas, de representaciones sociales que las

5 Como es bien conocido, la palabra "género" contaba, originalmente, con el significado de género gramatical. En la actualidad, por influencia de la palabra gender (inglés) se suele utilizar con el sentido de sexual. Así podemos escuchar expresiones como "violencia de género", "estudios sobre género", entre otros. Para una revisión exhaustiva sobre el uso y evolución de la palabra, ver Soledad de Andrés Castellanos (2002) y Pilar García Mouton (2002). 
harán mujeres aceptables. Existe una educación lingüística distinta para niños y niñas. A los primeros se les insta a ser más directos, utilizar más disfemismos y dar más órdenes. Por su parte, a las niñas se les estimula a ser más indirectas, utilizar más eufemismos y pedir las cosas amablemente. Ya en la adolescencia, se ha encontrado que los varones son más desafiantes, cambian de tema frecuentemente y son más egocéntricos, mientras que las mujeres son más cooperativas, sostienen por más tiempo un mismo tema y hablan de sus sentimientos y problemas personales (Romaine, 1996). Un dato que aparentemente otorgaría una superioridad lingüística a las niñas, es su tendencia a desarrollar más tempranamente su lenguaje y contar con un repertorio léxico más amplio. No obstante, como se puede apreciar en el entorno sociolingüístico adulto, se consume el prejuicio de que la mujer puede ser más parlanchina y, por lo tanto, tener un habla más insustancial. Estas tendencias discursivas constituirían una identidad en la que la mujer se asume como alguien que debe contenerse y como alguien débil de hecho o, al menos, de apariencia. Asumir la fragilidad como parte de la identidad femenina ha dado origen a identificar la cortesía discursiva, desprovista de asertos vigorosos, como una representación social en primera instancia femenina. La mujer tendería, entonces, a no imponer sus opiniones, sus reivindicaciones, a no obligar a su interlocutor, a estar de acuerdo con lo que le dicen, a preferir el ruego al uso del imperativo, pues así deja la decisión final en manos del oyente (Lakoff, 1981). Esta constitución de la identidad femenina, a través de representaciones sociales que son discursos, ha sido, y aún es, concomitante a una representación social actitudinal: la búsqueda de la belleza. Si la mujer se preocupa siempre por ser vehículo de los deseos de los otros (Martín Rojo, 1996), por agradar a los otros, por no molestar a los otros, es conclusión natural que la mujer se aliñe afanosamente. La otra cara de la moneda es que los otros, hombres y mujeres, se sientan con derecho de hablar de las características físicas y de indumentaria de las mujeres, aunque se estén reseñando, sobre las mismas, pasajes alusivos a su vida profesional (Romaine, 1996). Si esta búsqueda de la belleza la enfocamos como análoga a una búsqueda de la simetría, de las formas correctas, en general, se entendería que en diversos estudios de corte sociolingüís- 
tico se atribuya a la mujer un habla más cercana a la norma, al "habla correcta" (Labov, 1983).

Las formas de interacción discursiva de las mujeres deben contextualizarse en las relaciones de fuerza sociales en que ellas mismas se encuentran inmersas, de lo contrario correríamos el riesgo de minimizar la incidencia de tales representaciones sociales en la constitución de la identidad femenina. No estoy de acuerdo en el lamentable paso atrás que da Tannen cuando afirma, siguiendo a Goffman, que

(...) las maneras de hablar y de comportarse que se asocian al género no son una cuestión de identidad, sino de exhibición. En otras palabras, la conducta no es un reflejo de la naturaleza del individuo (identidad), sino de un cierto rendimiento que cumple el individuo (exhibición) (1996:195).

Es probable que en la medida en que la identidad femenina está en constante proceso de transición, las estrategias discursivas atribuidas a las mujeres aparezcan, en un contexto dado, como incongruentes con el poder y la independencia que las mismas puedan ejercer; sin embargo, el grado de "exhibición" de no correspondencia de tales recursos discursivos con las demás actitudes o realidad de la hablante, debe ser explicado de manera individual, subgrupal, o contextual, sin pretender que en todos los casos la mujer utiliza representaciones sociales al margen de una identidad. En todo caso, tales representaciones sociales serán siempre constitutivas de su identidad, ya sea porque ocultan o muestran una correspondencia con sus creencias y actitudes. No debe esperarse que las "maneras de hablar" y los comportamientos humanos, en general, muestren la identidad correspondiente sólo de manera directa y clara. Existe una tercera articulación del lenguaje por medio de la cual se construyen significados simbólicos que pueden estar en aparente contradicción con lo dicho (Barthes, 1986). Además, la ideología se comunica directa e indirectamente a través del discurso (T. Van Dijk, 1999).

\section{EL DISCURSO SOBRE LA BELLEZA FEMENINA}

Es cierto que desde la primera mitad del siglo XX asistimos a una rebelión, aunque subgrupal, en contra del acicalamiento femenino. La 
cantante Janis Joplin se jactaba de no usar faja ni sostén. Los cabellos largos que, al decir de Schopenhauer, son concomitantes a las ideas cortas de las mujeres, también fueron desterrados por no pocas mujeres. El ingreso de la mujer al mercado de trabajo y su incorporación en las universidades como intelectuales exigieron formas más prácticas para el arreglo femenino. No obstante, esta nueva resistencia femenina no ha significado la proscripción de la búsqueda de la belleza física femenina. De hecho, el fénomeno sociológico del juvenilismo, según el cual se pretende ser joven sin importar el paso de los años, ha incorporado también a un sector de la población masculina en esta búsqueda de la belleza física.

Actualmente, tanto en la televisión, las revistas, los rotativos, como en la radio, es común encontrar secciones o programas dedicados a la belleza. Algunas veces este tópico se mezcla con el de la salud, pues se sigue la consigna que muchos publicistas lanzan: salud es belleza y belleza es salud. En la vorágine urbana, la mujer asume sus responsabilidades ya sea del hogar, del trabajo, o de ambos lados, e intermitentemente se deja dibujar por los recursos mediáticos con los cuales interactúa, ya sea crítica o pasivamente.

El programa radiofónico "Frivolidades", del que aquí se analiza una pequeña muestra, se trasmite a una hora matutina en que las mujeres conducen a su trabajo, o conducen a llevar a los niños a la escuela, o han despedido a la familia de casa, o ya están instaladas en labores que permiten que mantenga la radio encendida (secretarias, dependientes de tiendas, recepcionistas, etcétera). El programa es escuchado principalmente por mujeres de clases media y media alta; esto se deduce por las zonas de la ciudad de las que se hacen las llamadas telefónicas. En la primera mitad del programa, la conductora presenta el tema e interpela a sus radioescuchas. Esta parte es un largo incipit en el que se dan estrategias discursivas muy ricas: se trata de un monólogo largo, con un dialogismo en el que la conductora supone las reacciones o estados de su público femenino. En la segunda parte asiste un invitado que es entrevistado por la conductora y responde a las preguntas capturadas por la telefonista.

Los temas abordados en la muestra de siete programas fueron: el cabello, los sombreros, la piel, remedios embellecedores, mentiras en 
torno a la belleza, los labios y el cuerpo. Una vez realizada la transcripción de los siete programas radiofónicos, fue posible identificar que existían recursos discursivos que se repetían; esta repetición nos sugería ya una posible sistematización analítica a través de la identificación de estrategias sociosemióticas específicas, cuyo eje axial es el discurso verbal y su respectiva prosodia. Es importante mencionar que sólo aquellas estrategias susceptibles de sistematización son las presentadas. Las estrategias discursivas que no se presentan de manera repetida o que aparecen en todo tipo de discurso, no son significativas aquí. Elegimos estrategias que presentaran las siguientes características: repetición, carga simbólica, carga ideológica, y que constataran las desventajas sociales y psicológicas de cierta construcción identitaria femenina. Estas estrategias son representaciones sociales que también encuentran correspondencia con otros símbolos que se manifiestan en las actitudes, el vestuario, el maquillaje o el peinado ${ }^{6}$, por ello las consideramos no sólo verbales, sino sociosemióticas.

\section{Estrategia sociosemiótica de la ignorancia}

No sólo el grupo femenino es susceptible a una tendencia sociosemiótica de la ignorancia en la cultura mediática. Bastante se discute sobre el papel de desinformación de los medios en general (Sartori, 2001), y sobre la estética del estupor en los jóvenes, que implica un culto a la torpeza (Avello y Muñoz, 2002). Sin embargo, es a las mujeres a quienes se les ha destinado consuetudinariamente el rol de ignorar. Parecería que para ser femenina es preciso desconocer, o parecer incapaz (Romaine, 1996; Lakoff, 1981 y McConnell-Ginet, 1992). Esto se confirma en el programa radiofónico analizado, en el que abundan las referencias con las que a las radioescuchas adultas se les llama "niña", "reina", "mija" (contracción de "mi hija"), entre otras. Estas referencias tienen la función sociodiscursiva de garantizar que la mujer permanezca con las limitaciones de una "nena". En el siguiente fragmento, la conductora saluda a su público:

6 Sin embargo, no es objetivo de este trabajo analizar las representaciones sociales no verbales. 
"A ver/ a ver/ ¿cómo se sienten ustedes?/ ¿hace cuánto que no te apapacha nadie? Que no te dicen a ver mi nena preciosa/ mi niña/ mi reina/ mi cosita/ a ver a ver (...) este es un espacio en donde las mujeres nos apapachamos". (Remedios embellecedores)

Otra recurso discursivo que confirma esta tendencia sociosemiótica es suponer que la interlocutoras son incapaces de reflexionar en asuntos evidentes como la sensibilidad corporal:

"te fijas que nuestro cuerpo nos sirve para sentir/ hacer/ machucarnos/ atropellar/ abrazar/ besar/ cargar/ trabajar/ y tantas cosas/ no te habías dado cuenta tú/ ¿verdad?/allá dentro/ tienes un espíritu/ un alma/ una energía”. (El cuerpo)

Después de afirmar que hablarán de un tema "súper importante7", la locutora invita a realizar preguntas, al mismo tiempo que presupone que las radioescuchas dudan de la inteligencia de las que serían sus propias interrogantes. Pero el gazapo no se detiene ahí. La locutora supone que las preguntas posibles pierden su torpeza, porque se tiene como objetivo "hacer hermosa" a la preguntona:

"no tengas complejos (...) ay pero son mensadas lo que voy a preguntar/ ¿¡qué dices!?/ ¿iqué dices!?/ ¿cómo que mensadas?/ ninguna cosa/ ninguna puede ser una tontera si es algo que te haga hermosa". (Remedios embellecedores)

Según puede concluirse con este ejemplo, la construcción de la identidad femenina, a través de la estrategia sociosemiótica de la ignorancia, sucede en los distintos participantes enunciativos, en las suposiciones sobre la segunda persona hipotética (las radioescuchas)

7 En su Gramática femenina (1991), López García y Morant han revisado prefijos, sufijos y acortamientos que caracterizan el habla de las mujeres. Súper, hiper, mega, entre otros prefijos, son más recurrentes en el habla femenina. Estos autores proponen la existencia tanto de una gramática verbal como no verbal que caracteriza a las mujeres. 
que hace la locutora, en la locutora misma y en las invitadas a su programa. En el siguiente caso, la locutora reprocha a la invitada que utilice vocablos "técnicos", que en realidad no lo son; la invitada se disculpa, asume el veto por utilizar un léxico ¿inaccesible para mujeres? Veamos el pasaje:

"Conductora: mira, mira/ ya/ ya se puso acá muy técnica/ patologías.

Invitada: perdón/ por enfermedades/ ¿sí?” (Remedios embellecedores)

Finalmente, me gustaría mostrar un ejemplo en el que la conductora asume de manera explícita la ignorancia como un tópico. La conductora está hablando sobre la relación que existe entre lo que se come y la piel, hace una alusión metadiscursiva ("desde mi muy modesto e ignorante punto de vista") con la que ella misma se resta capacidad intelectual y posesión de la información, y utiliza un recurso argumentativo por medio del cual atribuye su razón al sentimiento ("por lo que siento...)":

"Quizá, repito, no tiene nada que ver lo que te entra a la panza con lo que te sale por la piel/ pero yo opino/ desde mi muy modesto e ignorante punto de vista que/ por lo que siento que sí// que sí tiene que ver". (La piel)

\section{Estrategia sociosemiótica de la actuación}

La mujer se caracteriza por utilizar más variaciones prosódicas que el hombre y por contar con un registro tonal más agudo. Si bien con este recurso la mujer logra imprimir mayor expresividad en sus discursos, no podemos dejar de observar que en el entorno público laboral son el registro grave y la sobriedad en la entonación, las variantes que cuentan con mayor prestigio. El discurso directo ${ }^{8}$ es un recurso

8 Discurso directo es un concepto gramatical que sirve para identificar lo dicho por una segunda o tercera persona. Ejemplo: "Mi mamá me dijo: 'Estudia toda la lección antes de salir con tus amigos"'. Se trata de una cita literal de lo dicho por otros. En oposición, el discurso indirecto es cuando a través del relativo "que" se reconstruye lo dicho por tú o él: "Mi mamá me dijo que si no estudiaba no salía". 
discursivo que se encuentra ligado a la amplia gama prosódica que utiliza la mujer, porque cuando se utiliza el discurso directo lo suele acompañar de cierta entonación estereotipada que se refiere ya sea al tipo de hablante que se imita o al tono de discurso que se reproduce.

Entendemos aquí por actuación el acto discursivo de imitar la voz de otros, lo dicho por otros; esta imitación sucede muchas veces utilizando una prosodia, una entonación falsa, no propia de quien habla. La actuación discursiva se identifica en la escritura con el uso de comillas. Lingüísticamente, a este fenómeno se le identifica como discurso directo.

Actuación es aquí en gran medida sinónimo de imitación, aunque dejando evidencia de la imitación. No se trata de una imitación que oculta sus orígenes, sino, y en todo caso, se trata de una imitación que señala "Mira, estoy imitando al otro con mi habla". Este recurso se convierte en una estrategia sociosemiótica elocuente porque su esencia es dar voz a otras personas: yo actúo, hablo, como los otros para darle voz a esos otros. Su simbolismo no es poca cosa, pues contiene el antónimo del egocentrismo: cuando hablo no soy sólo yo, sino yo, tú y él. El símbolo es, en un sentido estereotípico, femenino. La voz femenina acoge a los demás. La exageración de este recurso llevaría a la anulación del yo femenino: "Con mi discurso, con mi voz, sólo soy los otros".

En nuestros datos es recurrente la utilización del discurso directo, es decir, la hablante constantemente imita la voz de otros; su alta frecuencia nos lleva a proponer que con el discurso directo se constituye una estrategia sociosemiótica de la actuación que caracteriza a la identidad femenina en nuestro corpus. Pero se trata aquí de una actuación, no como ejecución genuina en sí misma. En este sentido, actuar es asumir papeles que de suyo no nos pertenecen, y si la mujer se vale del discurso directo para asumir esos guiones que no son suyos, podemos advertir que la mujer construye su identidad también imitando o reproduciendo lo que otros dicen o podrían decir; es decir, la mujer atiende notablemente los actos de los otros; se aleja de ella misma y utiliza una primera persona que no le pertenece: cuando utilizo el discurso directo yo soy otro. 
En el siguiente fragmento, el discurso directo es hipotéticamente del "ser divino", Dios. Llama también la atención el polisíndeton" que impregna un tono infantil al discurso:

"Imagínate que fueras un alma flotando/ un angelito/ así como en las películas/y le dijeras al ser divino/dame chance de nacer /okay ándale pues/ te voy a meter en el cuerpo de una bebé/ y vas a crecer/y luego vas a ser una niña/y luego una mujer/y luego vas a ser mamá quizás/no lo sé/ no lo sél vamos a ver si te pongo algún hombre en el camino/ y luego vas a ser una ancianita/ y ya luego te regresas conmigo/ ¿zas?/zas/okay/ va/ y nace la bebé" (...) (El cuerpo)

La conductora del programa asume el posible discurso de sus radioescuchas, y da instrucciones sobre lo que podrían hablar las mujeres que atienden el programa. Así lo podemos apreciar en el siguiente pasaje:

"Me gustaría que agarrarás el teléfono y me dijeras/ pues mira, mi cuerpo la verdad/me sirve/ pues no me había dado cuenta que sirve para algo/ yo lo uso para/ pues para bañarme/ para cocinar/me sirve para cargar cosas" (...) (El cuerpo)

Las voces hipotéticas que asume la conductora son diversas: seres etéreos, Dios, radioescuchas, personajes televisivos, abuelitas y novios, entre otros. En el siguiente fragmento, la locutora plantea la necesidad de canalizar la energía vital en divertirse mucho, una diversión que, curiosamente, también radica en hacer sufrir a los otros con la ausencia de la mujer una vez que muere. El dato es relevante, pues sería una especie

9 Se comprende aquí como polisíndeton el recurso que implica la utilización reiterativa de la conjunción "y". Los niños suelen utilizar con frecuencia este recurso porque su repertorio de conectores lingüísticos es aún limitado. También lo encontramos en hablantes con poca cultura escritural. La cultura escritural lleva a utilización de conectores lingüísticos más sofisticados como: por lo tanto, de ahi que, de donde se desprenden, además, consecutivamente, en tanto que, y un largo etcétera. 
de "ajuste de cuentas" final, de alguien que dedica gran parte de su vida a satisfacer primero a los otros que a sí misma:

“(..) esa energía que tienes/ debe de servir para algo/ yo te lo digo/debe de servir primero para divertirte mucho/ para que cuando te vayas así en tus últimos momentos y digan /abuela ya se nos va/ tú digas/ sí pero me voy feliz/ abuelita fuiste el gusto de todos en esta familia/ mmm pa que sufran condenados/ sin mí (...)" (Mentiras en torno a la belleza)

Este caso y el que presento a continuación se eslabonan con la estrategia sociosemiótica de la diversión. Actuar y divertir se encuentran no pocas veces como recursos simultáneos para la mujer ideal. Además, la polifonía discursiva aquí presente muestra los intertextos que caracterizan al programa: películas; en este caso se trata de una película mexicana en la que "La Chorreada" y Pedro Infante son coprotagonistas y en la que se bromea sobre la causa por la que La Chorreada levanta los labios.

“(...) ¿por qué para las trompa/negra?/ ¿qué/ qué traes/ qué traes?/ ¿te salió un fuego?/ a ver/NOO BRUTO/quiero que me beses/yyyy/ah caray/con que eso traes ¿eh? Véngase mi Chorreada/ como decía Pedro Infante/ ¿verdad?” (Los labios)

\section{Estrategia sociosemiótica de la diversión}

Según hemos planteado, la ignorancia, la actuación y la diversión se constituyen como estrategias sociosemióticas a través de las cuales la mujer construye, de manera indirecta, su identidad. Si un hombre es serio se suele decir que es interesante; si una mujer es seria se suele decir que es aburrida. Sin importar que la mujer se encuentre realmente divertida, podemos afirmar es una petición social que la mujer sonría constantemente.

La sonrisa es parte constitutiva de una cortesía que, sin lugar a dudas, se exige más a la mujer. Así, no resulta extraño que en un programa de belleza femenina los temas se planteen de manera divertida y, al mismo tiempo, se invite a las interlocutoras a parecer divertidas siempre, sin importar si en realidad lo son. 
En el siguiente caso, la locutora subraya que ahí sólo se habla de "puro mitote embellecedor"10, es decir, interesa la interpretación ligera de las cosas, tal como también lo confirma su nombre "Frivolidades"

"En este programa sabe de qué hablamos/ hablamos de puro mitote embellecedor/ así de plano". (La piel)

Al mismo tiempo que la consigna constante en el programa es: "una mujer debe ser bella" -hecho que se confirma cuando la conductora dice “(...) los hombres/ feos fuertes y formales/ acá las muchachotas/ bellas y sensuales"-, se plantea, paradójicamente, que tener problemas con la belleza es divertido. Por ello son recurrentes las anécdotas imaginarias que sirven para reírse de los casos en los que la belleza no está presente:

"Imagínate que te pegaras una dona grasosita en la cara/ aaaight/no me saludes de beso/salúdame de lejecitos (...) y tú te acercas con tu mejilla de dona frita y dices jay qué pena!" (La piel)

“(...) alguno que otro más pulcro/ trae pañuelos desechables/ y se... y se/ pues no se enjuga/ porque no es jugo/ ¿verdad?” (La piel)

"¿por qué a alguien le sale la piel grasa y por qué a otros no?/ en pocas palabras// porque te adelantaron la herencia chata/ por eso/ es pura herencia/si tú decías ¿qué me irá a tocar/ algún milloncito de pesos?/ pues no/ te tocó piel grasa/ chula". (La piel)

De la misma manera que el tópico de la ignorancia aparece como una representación social que la mujer comparte con el grupo de los

10 En México es recurrente el uso del adjetivo "puro" como adverbio equivalente a "únicamente"; "mitote" es una palabra de origen náhuatl, mitotl, que originalmente aludía a una fiesta en la que se danzaba alrededor de un vasija de la que bebían los participantes hasta embriagarse. Actualmente "mitote" significa chisme, cotilleo. "Te ves el cuerpo?/ oye/ ¿ya se te olvidó?/ ¿cómo son tus pompas? (...) ¿hace cuánto que no me veo las pompeyanas?” (Mentiras en torno a la belleza) 
jóvenes, el tópico de la diversión ${ }^{11}$ se comparte con el grupo de los niños y de los jóvenes. Esta situación es trascendente porque vendría a confirmar la construcción de un tejido simbólico social en el que las mujeres, los jóvenes y los niños pueden gastarse la vida tonteando y divirtiéndose, mientras que los hombres adultos serían tan inteligentes y sobrios como el timón laboral, económico e intelectual lo exija. Como podemos observar, en cada programa se trata de persuadir explícitamente para que la mujer se divierta:

“(...) esa energía que tienes/ debe de servir para algo/ yo te lo digo/debe de servir primero para divertirte mucho". (Mentiras en torno a la belleza)

“¿cómo amaneciste?/ ou pues hay pasándola/ NADA de que pasándola/diviértete/ cada uno de tus días se te regaló para que te diviertas, para que ames gente/ para que le des amoor a esa gente/ para que te rías”. (El cabello)

\section{LA AUTODEFINICIÓN GRUPAL}

Es de esperarse que un programa radiofónico de belleza que se trasmite en una radiodifusora que se llama "Radio Mujer", se hagan referencias constantes a lo que la mujer es o debe ser. La radiodifusora se asume como ruta del ser femenino. No son pocas las veces en que la mujer es definida en oposición al hombre. Además de bella, la mujer debe ser sensual, mientras que a los hombres se les da la concesión de ser "feos, fuertes y formales":

"En Radio Mujer estamos tratando de darle a la mujer, sobre todo/ un punto más/ para identificarse/ y en este espacio de belleza/ bueno/ pues qué más identificación que/ que el de la belleza femenina/ es realmente algo muy muy de las mujeres/ los hombres/ feos fuertes y formales/ acá las muchachotas/ bellas y sensuales". (La piel)

11 Avello y Muñoz (2002) se refieren a la estética de la burla como una de las respuestas no racionales que los jóvenes dan a los contradictorios mensajes que los mismos reciben de parte de distintas instituciones como la familia y los medios masivos de comunicación. 
A lo largo de las transcripciones, encontramos que una mujer, si optara por ser cosmetóloga, debe ser muy "Ética/ nada de mentirosa/ nada de conflictiva/ y muuy limpia/ que le guste su imagen". (Remedios embellecedores). En general, aparecen explícitamente pasajes en los que se establece que la mujer debe retrasar el envejecimiento, atender su cuerpo, tener mucha energía, ser feliz, tener autoestima, tener buenos modales y maquillarse bien. El trasfondo negativo de estas proposiciones que dan forma a la identidad femenina es, según ya hemos visto, que conllevan la desatención de la mujer como sujeto en sí y la atención en la satisfacción de los otros; el hecho se corrobora cuando la conductora invita a hombres a que llamen al programa para escuchar su opinión, en este caso, sobre los labios de las mujeres

"Y a los hombres ¿qué les gustará mas?/ quisiera que nos hablara un hombre y nos dijera/ ¿te gusta cuando la mujer trae los labios pintados?/¿te asusta?/ porque no sabes cómo vas a quedar" (Los labios). "Los hombres dicen queee/ no hay nada más sexy (...) que ver cómo una mujer/ lenta/ pero muy lentamente/ se pasa el labial/sobre los labios"

\section{CONCLUSIONES}

La construcción de la identidad femenina se realiza con representaciones sociales diversas que pueden ser directas, en el caso de que un grupo se defina explícitamente, o indirectas, cuando un grupo utiliza diversas actitudes y símbolos que los caracteriza. En el primer caso, los medios utilizados son escriturales o verbales en periódicos, libros, discursos radiofónico y parlamentario, entre otros. En el segundo caso se utiliza también el discurso aunque en la dimensión de lo tácito, de lo simbólico. A través de ambos tipos de representación social, la mujer establece una dinámica de creencias y actitudes por medio de las cuales se construye para los otros. Se trata de una maquinaria cuyo sistema de transmisión son las estrategias sociosemióticas revisadas aquí, las que se refieren a la ignorancia, a la actuación y a la diversión.

El programa analizado, "Frivolidades", se transmite diariamente a lo largo de una hora, es decir, cada día las mujeres que lo escuchan reci- 
ben símbolos y estrategias sociosemióticas repetitivas, con las cuales se garantiza que la mujer se asuma como ignorante, divertida y mimética. El hecho contrasta con las predicaciones, también encontradas en el corpus, con las que se afirma que la mujer sí puede o debe tener una vida profesional exitosa. En ese sentido, la construcción de la identidad femenina que se propone en los medios es tan incongruente, que lejos de ser un coadyuvante para el desarrollo de la identidad de la mujer, resulta ser un disparador de contradicciones insalvables que sumen a la mujer en un conflicto psicosocial. La construcción social del tejido discursivo femenino muestra que las creencias y valores difundidos, legitimados, no son congruentes entre sí. Por un lado, se exige a la mujer ser bella, tonta y divertida; pero, por el otro, se le exige tener iniciativa, ser lista y desenvolverse laboralmente. No obstante esta naturaleza no es exclusiva de la construcción social del tejido discursivo femenino, se aplica en general a todos los tejidos discursivos porque los mismos se reproducen en función de códigos diversos de existencia social: el código económico del mercado, los códigos persuasivos publicitarios, los códigos morales familiares, los códigos morales religiosos y los códigos laborales, entre otros. La cultura urbana contemporánea implica esta complejidad simbólica que se desglosa en un hojaldrado tejido sociodiscursivo.

Por otro lado, la coincidencia de que en la cultura mediática global se estén proponiendo estrategias o tendencias sociosemióticas dirigidas a distintos grupos, como jóvenes, niños y mujeres, confirma que existe un entorno de aletargamiento masivo; cuyas repercusiones mayores aún no conocemos. Cabría preguntarse si existe una tendencia a difuminar las identidades grupales diversas. Cabría preguntarse si estamos en el peligroso camino de construir una identidad global mediática y única, cuya esencia sea la negación de la inteligencia humana.

Los trazos regionales encontrados en la construcción de la identidad femenina son pocos. Sin lugar a dudas obedece a que se analizó un recurso mediático. El matiz regional se encuentra, tal vez, en el énfasis y la naturalidad con las que se plantea el desarrollo de una identidad femenina basada en la atención a sí misma, aunque para lograr los medios necesarios y suficientes para complacer a los otros. 


\section{Bibliografía}

ANDRÉS Castellanos, S. de (2002) “¿Violencia de género?” en A.M. Vigara Tauste y R. Ma. Jiménez Catalán (eds.) "Género", sexo, discurso. Madrid: Laberinto.

AVELLO Flórez, J. y A. Muñoz Garrión. (2002) “La comunicación desamparada. Una revisión de paradojas en la cultura juvenil" en F. Rodríguez. Comunicación y cultura juvenil. Barcelona: Ariel.

BALIBAR, E. (2005) Violencias, identidades y civilidad. Para una cultura política global. Barcelona: Gedisa.

BARTHES, R. (1986) Mitologías. México: Siglo Veintiuno Editores.

CÓRDOVA Abundis, P. y M.A. Corona Zenil (2002) "El habla coloquial femenina en el discurso de Las niñas bien de Guadalupe Loaeza" en Signos literarios y lingüisticos, núm. 4, vol. 2. México: Universidad Autónoma Metropolitana.

- (2003) Habla y sociedad. El análisis lingüistico-social del habla. Mèxico: Universidad de Guadalajara.

BAJTín, M.M. (2000) Yo también soy (fragmentos sobre el otro). México: Taurus.

BourdieU, P. (1990) Sociología y cutura. México: Consejo Nacional para la Cultura y las Artes-Grijalbo.

- (2000) Poder, derecho y clases sociales. Bilbao: Desclée.

GARCía Mouton, P. (1999) Cómo hablan las mujeres. Madrid: Arco Libros.

- (2002) "Género como traducción de gender: ¿anglicismo incómodo?”. En A.M. Vigara Tauste y R. Ma. Jiménez Catalán (eds.) “Género", sexo, discurso. Madrid: Laberinto.

GonZÁLEZ Calvo, J.M. (1998) "Género, sexo e ignorancia gramatical" en Variaciones en torno a la gramática española. Cáceres: Universidad de Extremadura.

HALlidAY, M. A. K. (1982) El lenguaje como semiótica social. La interpretación social del lenguaje y del significado. México: Fondo de Cultura Económica.

LABOV, W. (1983) Modelos sociolingüísticos. Madrid: Cátedra.

LAKOFF, R. (1981) El lenguaje y el lugar de la mujer. Barcelona: Hacer.

LÓPEZ García, A. y R. Morant (1991) Gramática femenina. Madrid: Cátedra. 
MARINA, J.A. (2000) Crónicas de la ultramodernidad. Barcelona: Anagrama.

MARTÍN Rojo, L. (1996) "Lenguaje y género. Descripción y explicación de la diferencia” en Signos. Teoría y práctica de la educación, núm. 16.

MCCONNELL-Ginet, S. (1992) "Lenguaje y género" en Panorama de la lengua moderna de la Universidad de Cambridge, tomo IV. El lenguaje: contexto socio-cultural. Madrid: Visor.

ROMAINE, S. (1996) "Lengua y género" en El lenguaje en la sociedad. Una introducción a la sociolingüística. Barcelona: Ariel.

SARTORI, G. (2001) Homo videns. La sociedad teledirigida. México: Taurus.

TANNEN, D. (1996) Género y discurso. Barcelona: Paidós.

VAN DIJK, T.A. (1983) La ciencia del texto. Barcelona: Gedisa.

- (1999) Ideología. Una aproximación multidisciplinaria. Barcelona: Gedisa.

VigARA Tauste, A.M. y R. Ma. Jiménez Catalán (eds.) (2002) “Género”, sexo, discurso. Madrid: Laberinto. 